\title{
Suprascapular nerve block is a clinically attractive alternative to interscalene nerve block during arthroscopic shoulder surgery: a meta-analysis of randomized controlled trials
}

\author{
Changjiao Sun ${ }^{1} \mathbb{D}$, Xiaolin $\mathrm{Ji}^{2}$, Xiaofei Zhang ${ }^{3}$, Qi Ma ${ }^{1}$, Peng Yu ${ }^{4}$, Xu Cai $^{i^{*+}+}$ and Huadong Yang ${ }^{1 *+}$
}

\begin{abstract}
Background: The interscalene brachial plexus block (ISB) is a commonly used nerve block technique for postoperative analgesia in patients undergoing shoulder arthroscopy surgery; however, it is associated with potentially serious complications. The use of suprascapular nerve block (SSNB) has been described as an alternative strategy with fewer reported side effects for shoulder arthroscopy. This review aimed to compare the impact of SSNB and ISB during shoulder arthroscopy surgery.

Methods: A meta-analysis was conducted to identify relevant randomized controlled trials involving SSNB and ISB during shoulder arthroscopy surgery. Web of Science, PubMed, Embase, Cochrane Controlled Trials Register, Cochrane Library, Highwire, CNKI, and Wanfang database were searched from 2010 through March 2021.

Results: We identified 1255 patients assessed in 17 randomized controlled trials. Compared with the ISB group, the SSNB group had higher VAS at rest in PACU $(P=0.003), 1 \mathrm{~h}$ after operation $(P=0.005)$, similar pain score $2 \mathrm{~h}(P=0.39)$, 3-4 $\mathrm{h}(P=0.32), 6-8 \mathrm{~h}$ after operation $(P=0.05)$, then lower VAS $12 \mathrm{~h}$ after operation $(P=0.00006)$, and again similar VAS 1 day $(P=0.62)$ and 2 days after operation $(P=0.70)$. As for the VAS with movement, the SSNB group had higher pain score in PACU $(P=0.03)$, similar VAS $4-6 \mathrm{~h}$ after operation $(P=0.25)$, then lower pain score 8-12 $\mathrm{h}$ after operation $(P=0.01)$ and again similar VAS 1 day after operation $(P=0.3)$ compared with the ISB group. No significant difference was found for oral morphine equivalents use at $24 \mathrm{~h}(P=0.35)$, duration of PACU stay $(P=0.65)$, the rate of patient satisfaction ( $P=0.14)$ as well as the rate of vomiting $(P=0.56)$, and local tenderness $(P=0.87)$. However, the SSNB group had lower rate of block-related complications such as Horner syndrome $(P<0.0001)$, numb $(P=0.002)$, dyspnea $(P=0.04)$, and hoarseness $(P=0.04)$.
\end{abstract}

\footnotetext{
* Correspondence: sunchangjiao@163.com; yanghuadong2020@sina.com

${ }^{+}$Xu Cai and Huadong Yang contributed equally to this work.

'Department of Orthopedic, Beijing Tsinghua Changgung Hospital, School of

Clinical Medicine, Tsinghua University, No. 168 Litang Road, Dongxiaokou

Town, Changping District, Beijing 102218, China

Full list of author information is available at the end of the article
}

C C The Author(s). 2021 Open Access This article is licensed under a Creative Commons Attribution 4.0 International License, which permits use, sharing, adaptation, distribution and reproduction in any medium or format, as long as you give appropriate credit to the original author(s) and the source, provide a link to the Creative Commons licence, and indicate if changes were made. The images or other third party material in this article are included in the article's Creative Commons licence, unless indicated otherwise in a credit line to the material. If material is not included in the article's Creative Commons licence and your intended use is not permitted by statutory regulation or exceeds the permitted use, you will need to obtain permission directly from the copyright holder. To view a copy of this licence, visit http://creativecommons.org/licenses/by/4.0/. The Creative Commons Public Domain Dedication waiver (http://creativecommons.org/publicdomain/zero/1.0/) applies to the data made available in this article, unless otherwise stated in a credit line to the data. 
Conclusion: Our high-level evidence established SSNB as an effective and safe analgesic technique and a clinically attractive alternative to interscalene block with the SSNB'S advantage of similar pain control, morphine use, and less nerve block-related complications during arthroscopic shoulder surgery, especially for severe chronic obstructive pulmonary disease, obstructive sleep apnea, and morbid obesity. Given our meta-analysis's relevant possible biases, we required more adequately powered and better-designed RCT studies with long-term follow-up to reach a firmer conclusion.

Keywords: Nerve block, Regional, Suprascapular, Interscalene, Shoulder, Arthroscopy

\section{Background}

Shoulder arthroscopic surgery can be associated with a $45 \%$ incidence of severe intraoperative and postoperative pain that can interfere with recovery and rehabilitation, which can be challenging to manage without large dose opioids. So, controlling postoperative pain while minimizing opioid administration is incredibly essential. Supplementing general anesthesia (GA) with a regional nerve block is recommended for reducing anesthesia's intra-operative requirements, improving the quality of postoperative pain relief, easing postoperative rapid recovery $[4,5,40]$.

Regional anesthetic techniques can control pain effectively, both at rest and on movement, allowing earlier mobilization without the adverse effects of opioids [36]. Among the various types of regional anesthetic techniques, the interscalene brachial plexus block (ISB) is a standard used nerve block technique for postoperative analgesia in patients undergoing shoulder surgery, as it has consistently been shown to significantly control

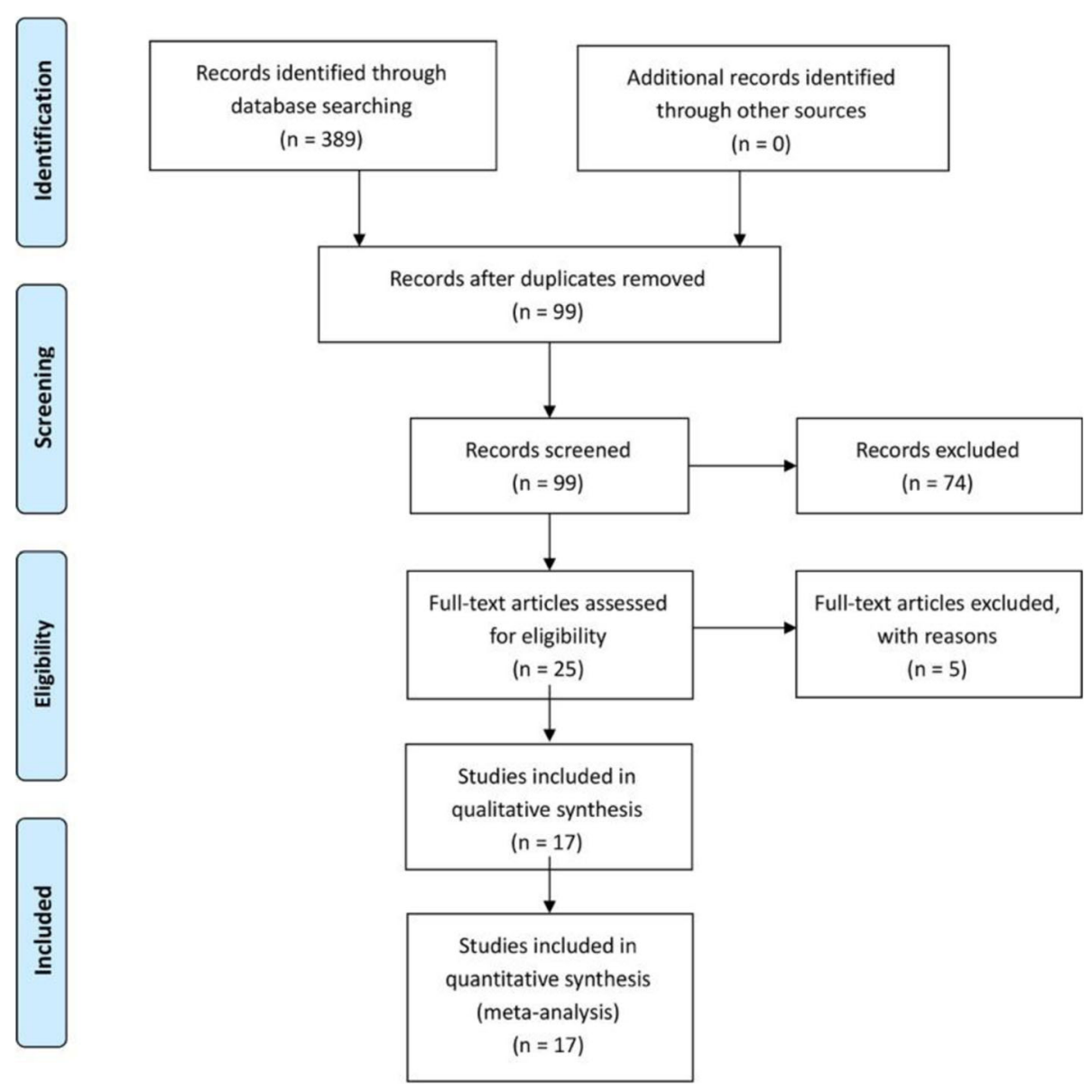

Fig. 1 The search results and selection procedure. The literature search identified 389 citations. Of these, 290 duplicates were removed. After reviewing the 99 remaining articles' titles and abstracts, we excluded 74 papers according to the inclusion and exclusion criteria; 25 full texts were retrieved. Because some articles did not compare the suprascapular nerve block with interscalene nerve block, five studies were excluded. Finally, we identified 1255 patients assessed in 17 randomized controlled trials 


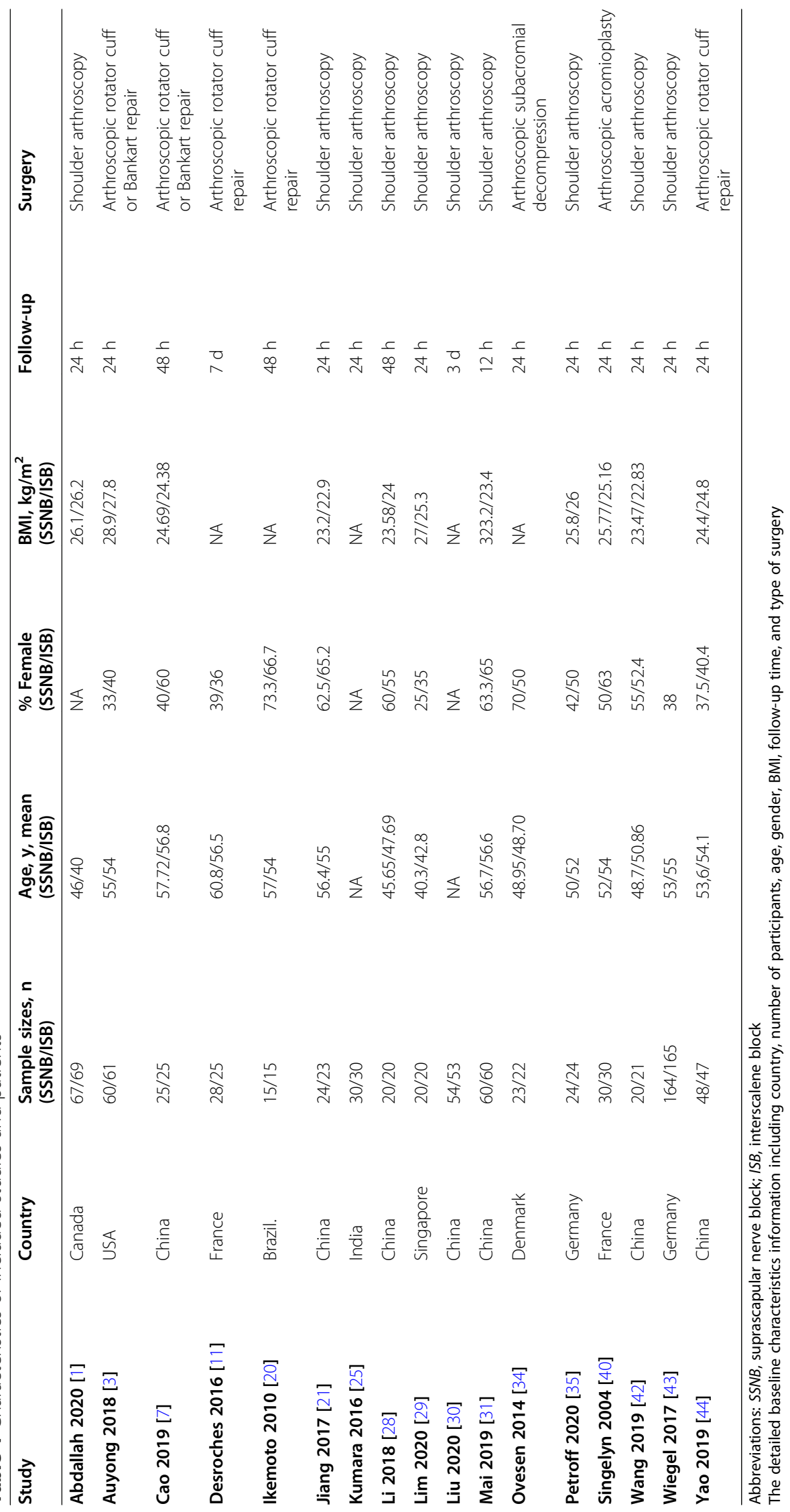


Table 2 Details of the nerve blocks and anesthesia used

\begin{tabular}{|c|c|c|c|c|}
\hline Study & $\begin{array}{l}\text { Localization } \\
\text { method }\end{array}$ & $\begin{array}{l}\text { Analgesia used in } \\
\text { nerve block }\end{array}$ & Analgesia used in PACU & Analgesia used in ward \\
\hline $\begin{array}{l}\text { Abdallah } \\
2020[1]\end{array}$ & $\begin{array}{l}\text { Ultrasound } \\
\text { guided }\end{array}$ & $\begin{array}{l}\text { Local anesthetic } \\
\text { solution in } 5-\mathrm{ml} \\
\text { aliquots }\end{array}$ & $\begin{array}{l}\text { NRS }>4 \text {, IV fentanyl in } 25-\mu \mathrm{g} \text { increments } \\
\text { every } 5 \text { min, as needed, up to a total of } 100 \\
\mu \mathrm{g} \text {, followed by IV morphine in } 5-\mathrm{mg} \text { incre- } \\
\text { ments every } 10 \text { min up to a total of } 20 \mathrm{mg} \text { or } \\
\text { hydromorphone in } 0.2-\mathrm{mg} \text { increments every } \\
10 \text { min up to a total of } 3 \mathrm{mg} \text {. }\end{array}$ & $\begin{array}{l}\text { Oral acetaminophen } 300 \mathrm{mg} \text { plus codeine } \\
30 \mathrm{mg} \text { combination tablets every } 4 \mathrm{~h} \text {, as } \\
\text { needed, followed by oral oxycodone } 5 \text { to } 10 \\
\text { mg every } 4 \mathrm{~h} \text {, as needed. }\end{array}$ \\
\hline
\end{tabular}

\begin{tabular}{|c|c|c|}
\hline $\begin{array}{l}\text { Auyong } \\
2018 \text { [3] }\end{array}$ & $\begin{array}{l}\text { Ultrasound } \\
\text { guided }\end{array}$ & $\begin{array}{l}15 \mathrm{~mL} \text { of } 0.5 \% \\
\text { ropivacaine }\end{array}$ \\
\hline $\begin{array}{l}\text { Cao } 2019 \\
{[7]}\end{array}$ & $\begin{array}{l}\text { Arthroscopic } \\
\text { guided (SNNB)/ } \\
\text { Ultrasound } \\
\text { guided (ISB) }\end{array}$ & $\begin{array}{l}20 \mathrm{~mL} \text { of } 0.2 \% \\
\text { ropivacaine }\end{array}$ \\
\hline $\begin{array}{l}\text { Desroches } \\
2016[11]\end{array}$ & $\begin{array}{l}\text { Ultrasound } \\
\text { quided }\end{array}$ & $\begin{array}{l}20 \mathrm{~mL} \text { of } 0.75 \\
\text { ropivacaine. }\end{array}$ \\
\hline
\end{tabular}

\begin{tabular}{|c|c|c|c|}
\hline $\begin{array}{l}\text { Ikemoto } \\
2010[20]\end{array}$ & $\begin{array}{l}\text { Anatomic } \\
\text { landmarks guided }\end{array}$ & $\begin{array}{l}2 \mathrm{mg} / \mathrm{kg} \text { of } 0.5 \% \\
\text { ropivacaine }\end{array}$ & NA \\
\hline $\begin{array}{l}\text { Jiang } 2017 \\
{[21]}\end{array}$ & $\begin{array}{l}\text { Ultrasound } \\
\text { guided }\end{array}$ & $\begin{array}{l}20 \mathrm{~mL} \text { of } 0.375 \% \\
\text { ropivacaine }+5 \mathrm{mg} \text { of } \\
\text { dexamethasone }\end{array}$ & If $\mathrm{VAS}>4,50 \mathrm{mg}$ of pethidine IM \\
\hline $\begin{array}{l}\text { Kumara } \\
2016[25]\end{array}$ & $\begin{array}{l}\text { Electrophysiology- } \\
\text { guided }\end{array}$ & $\begin{array}{l}20 \mathrm{~mL} \text { of } 0.5 \% \\
\text { bupivacaine with } 75 \\
\text { mg of clonidine }\end{array}$ & If $\mathrm{VAS}>4,75 \mathrm{mg}$ of diclofenac IM \\
\hline $\begin{array}{l}\text { Li } 2018 \\
\text { [28] }\end{array}$ & $\begin{array}{l}\text { Ultrasound } \\
\text { guided }\end{array}$ & $\begin{array}{l}20 \mathrm{~mL} \text { of } 0.375 \% \\
\text { ropivacaine }\end{array}$ & If VAS $>4$, tramadol IV \\
\hline $\operatorname{Lim}_{[29]} 2020$ & $\begin{array}{l}\text { Ultrasound } \\
\text { guided }\end{array}$ & $\begin{array}{l}15 \mathrm{ml} \text { of } 0.5 \% \\
\text { ropivacaine }\end{array}$ & Intravenous morphine (up to $0.2 \mathrm{mg} / \mathrm{kg}$ ) \\
\hline $\begin{array}{l}\text { Liu } 2020 \\
{[30]}\end{array}$ & $\begin{array}{l}\text { Ultrasound } \\
\text { guided }\end{array}$ & $\begin{array}{l}6 \mathrm{~mL} \text { of } 0.3 \% \\
\text { ropivacaine }\end{array}$ & NA \\
\hline $\begin{array}{l}\text { Mai } 2019 \\
{[31]}\end{array}$ & $\begin{array}{l}\text { Ultrasound } \\
\text { guided }\end{array}$ & $\begin{array}{l}20 \mathrm{~mL} \text { of } 0.375 \% \\
\text { ropivacaine }+5 \mathrm{mg} \text { of } \\
\text { dexamethasone }\end{array}$ & NA \\
\hline $\begin{array}{l}\text { Ovesen } \\
2014[34]\end{array}$ & $\begin{array}{l}\text { Anatomic } \\
\text { landmarks guided }\end{array}$ & $\begin{array}{l}20 \mathrm{~mL} \text { of } \\
\text { bupivacaine (SSNB)/ } \\
30 \mathrm{~mL} \text { of ropivacaine } \\
\text { (ISB) }\end{array}$ & NA \\
\hline $\begin{array}{l}\text { Petroff } \\
2020[35]\end{array}$ & $\begin{array}{l}\text { Ultrasound } \\
\text { guided }\end{array}$ & $\begin{array}{l}10 \mathrm{ml} \text { of } 1 \% \\
\text { ropivacaine }\end{array}$ & NA \\
\hline $\begin{array}{l}\text { Singelyn } \\
2004[40]\end{array}$ & $\begin{array}{l}\text { Anatomic } \\
\text { landmarks guided }\end{array}$ & $\begin{array}{l}10 \mathrm{~mL} \text { of } 0.25 \% \\
\text { bupivacaine (SSNB)/ } \\
20 \mathrm{~mL} \text { of } 0.25 \% \\
\text { bupivacaine (ISB) }\end{array}$ & $\begin{array}{l}\text { If VAS }>3,2 \mathrm{~g} \text { of IV propacetamol, } 30 \mathrm{~min} \text {, if } \\
\text { VAS }>35 \text { or } 10 \mathrm{mg} \text { of subcutaneous } \\
\text { morphine }\end{array}$ \\
\hline $\begin{array}{l}\text { Wang } \\
2019[42]\end{array}$ & $\begin{array}{l}\text { Ultrasound } \\
\text { guided }\end{array}$ & $\begin{array}{l}15 \mathrm{~mL} \text { of } 0.5 \% \\
\text { ropivacaine }\end{array}$ & If $\mathrm{VAS}>3$, tramadol IV \\
\hline $\begin{array}{l}\text { Wiegel } \\
2017[43]\end{array}$ & $\begin{array}{l}\text { Ultrasound } \\
\text { guided }\end{array}$ & $\begin{array}{l}10 \mathrm{~mL} \text { of } 1 \% \\
\text { ropivacaine/20 } \mathrm{mL} \text { of } \\
0.75 \% \text { ropivacaine }\end{array}$ & If NRS $>3,3 \mathrm{mg}$ of IV piritramide \\
\hline $\begin{array}{l}\text { Yao } 2019 \\
{[44]}\end{array}$ & $\begin{array}{l}\text { Ultrasound } \\
\text { guided }\end{array}$ & $\begin{array}{l}15 \mathrm{~mL} \text { of } 0.5 \% \\
\text { ropivacane }(\mathrm{SSNB}) / 20 \\
\mathrm{~mL} \text { of } 0.5 \% \\
\text { ropivacaine (ISB) }\end{array}$ & $\begin{array}{l}\text { If VAS }>3,100 \mathrm{mg} \text { of tramadol IV, } 10 \mathrm{~min} \text {, if } \\
\text { VAS }>3,3 \mathrm{mg} \text { of morphine IV. }\end{array}$ \\
\hline
\end{tabular}

NRS score 4-6, 5 mg of oral oxycodone; NRS score 7-10, $10 \mathrm{mg}$ of oral oxycodone.

$100 \mathrm{mg}$ of imrecoxib orally. If VAS $>3,50$ $\mathrm{mg}$ of flurbiprofen axetil $\mathrm{N} ; 6 \mathrm{~h}$ later, if VAS $>3$, another $50 \mathrm{mg}$ of flurbiprofen axetil IV: if $\mathrm{VAS}>5,50 \mathrm{mg}$ of pethidine IM

$1 \mathrm{~g}$ of acetaminophen, $100 \mathrm{mg}$ of ketoprofen, Acetaminophen (325 mg, 6 times a day), $100 \mathrm{mg}$ of tramadol IV. If VAS $>3,3 \mathrm{mg}$ of morphine IV; 5 min later, if VAS > 3, another $3 \mathrm{mg}$ of morphine IV

ketoprofen (100 mg, twice a day), pantoprazole(20 mg, once a day), tramadol (37.5 mg, 6 times a day). If still in pain, oral morphine sulfate (10 mg, 6 times a day).

NA

If $\mathrm{VAS}>4,50 \mathrm{mg}$ of pethidine IM

If VAS> 4, 75 mg of diclofenac IM

If VAS > 4, tramadol IV

Regular oral paracetamol $1 \mathrm{~g}$ every $6 \mathrm{~h}$ and etoricoxib $120 \mathrm{mg}$ once daily

NA

NA

$1 \mathrm{~g}$ of paracetamol 4 times a day, $600 \mathrm{mg}$ of ibuprofen 3 times a day. If VAS $>3$, patients received 3-5 mg nicomorphine hydrochloride IV followed by $5 \mathrm{mg}$ ketobemidone.

Ibuprofen $600 \mathrm{mg}$ up to four times or the synthetic opioid tilidine $100 \mathrm{mg}$ up to twice in $24 \mathrm{~h}$, as needed.

If VAS $>3,2 \mathrm{~g}$ of IV propacetamol, $30 \mathrm{~min}$, if VAS $>35$ or $10 \mathrm{mg}$ of subcutaneous morphine

If VAS > 3, tramadol IV

If NRS > 3, 3 mg of IV piritramide

$300 \mathrm{mg}$ of oral ibuprofen 3 times a day, if VAS > 3, $100 \mathrm{mg}$ of Tramadol IV; $10 \mathrm{~min}$, if $\mathrm{VAS}>3,2 \mathrm{mg}$ of hydromorphone hydrochloride IM

Abbreviations: SSNB, suprascapular nerve block; ISB, interscalene block; IV, intravenous; IM, intramuscular; NRS, numerical rating scale; VAS, visual analog Scale.; $P A C U$, postanesthesia care unit; US, ultrasound

Details of the nerve blocks and anesthesia used including localization method, analgesia, used in nerve block, analgesia used in PACU and analgesia used in ward 


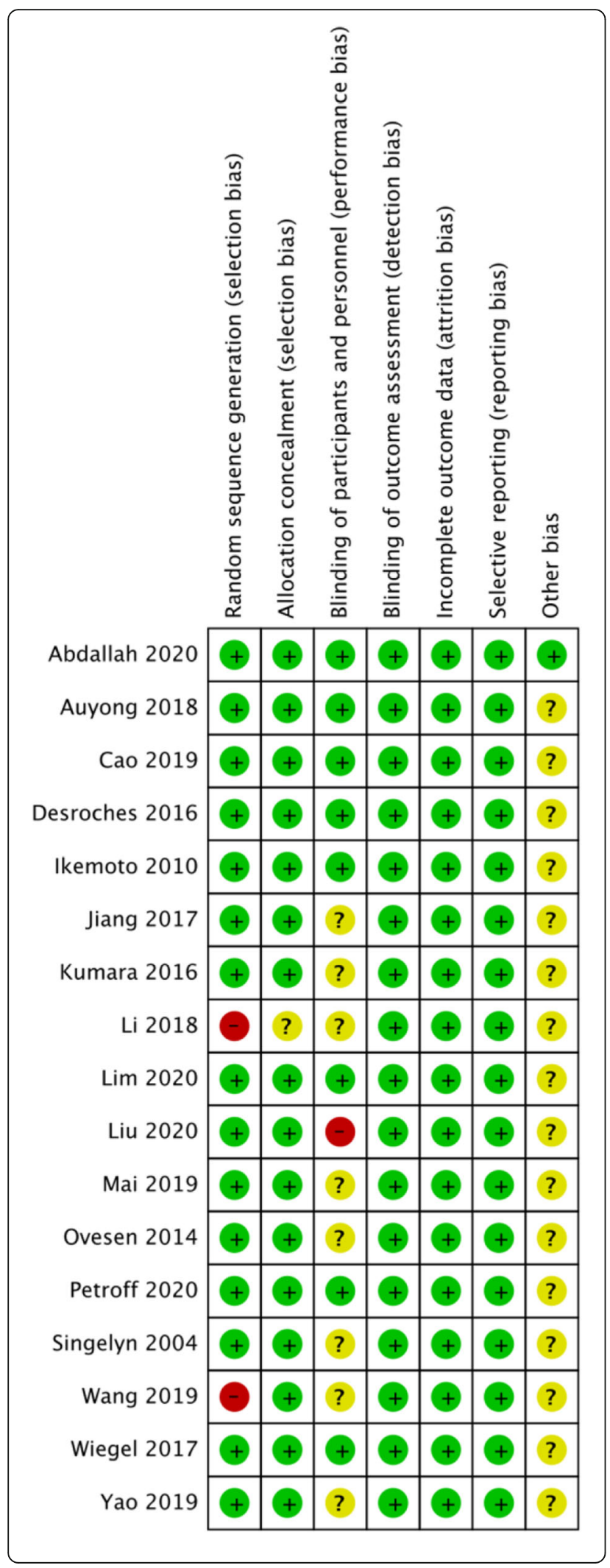

Fig. 2 Risk of bias summary for included studies. +, no bias; -, bias; ?, bias unknown. Fifteen studies adequately described the correct randomization. Sixteen studies demonstrated sufficient allocation concealment. Eight studies described the blinding of participants and personnel. All seventeen articles described the blinding of outcome assessment, retained complete outcome data, and avoided selective reporting. We rated as unclear risk of other bias because we cannot ignore other potential dangers of biases

postoperative pain, even in a small dose or single dose $[2,17,18,24,26]$. Moreover, ISB can be used to provide either surgical anesthesia or postoperative anesthesia. Many studies have demonstrated that ISB provides optimal analgesia in shoulder arthroscopic surgery in success rates of $87-100 \%$ [36]. Although it is useful for postoperative analgesia, ISB is challenging to perform, and it is associated with potentially serious complications such as diaphragmatic paresis from the phrenic nerve block, pneumothorax, brachial plexus injury, extended motor block inadvertent epidural anesthesia, and vertebral artery injection [15, 27]. Furthermore, there are relative contraindications in patients with severe chronic obstructive pulmonary disease because of phrenic nerve issues [15]. This clinical problem has recently received considerable attention, with several calls to seek alternatives to interscalene block in shoulder arthroscopy [9]. So, the need for a safer ISB alternative has prompted researchers to examine several options, including but not limited to the suprascapular block [14]. The suprascapular nerve block (SSNB) technique is a simple, easily reproducible technique that is thought to supply sensory fibers to approximately $70 \%$ of the shoulder joint and directly innervates the supraspinatus and infraspinatus muscles. The most common complication of SSNB is transient nerve palsy [6].We found few studies comparing the efficacy of SSNB and ISB for arthroscopic shoulder surgery. Some have found ISB to be superior [23, 39], whereas others have shown that SSNB provides noninferior analgesia $[11,25]$. Our meta-analysis was to compare the analgesic efficacy of SSNB with ISB after shoulder arthroscopy.

\section{Methods}

The current meta-analysis was registered on PROSPERO (International prospective register of systematic reviews) and the registration number was CRD42020205426.This meta-analysis was performed using a predetermined protocol following the PRISMA (Preferred Reporting Items for Systematic Reviews and Meta-Analyses) statement to assess the results' quality to make sure our meta-analysis's results reliable and veritable.

\section{Search strategy}

SSNB and ISB during shoulder arthroscopy surgery. Web of Science, PubMed, Embase, Cochrane Controlled 
Trials Register, Cochrane Library, Highwire, CNKI, and Wanfang database were searched from 2010 through March 2021. The keywords used were "nerve block," "regional," "suprascapular," "interscalene," "shoulder," "arthroscopic," randomized controlled trials" in conjunction with Boolean operators "AND" or "OR." We used Review Manager Software for MAC to perform the meta-analysis.

\section{Inclusion criteria}

Studies were eligible if (1) the intervention was patients undergoing shoulder arthroscopic surgery with SSNB; (2) the comparator was patients undergoing shoulder arthroscopic surgery with ISB; (3) the study design was a randomized controlled trial (RCTs); and (4) the studies were required to contain at least one clinical outcome data. The exclusion criteria were as follows: (1) observational studies; (2) non-RCTs; and (3) studies with insufficient clinical outcome data.

\section{Data extraction process}

Two reviewers (C.J.S and Q.M.) used a standardized form to extract data. A third reviewer (H.D.Y.) was used to resolve disagreements in eligibility, data extraction, or quality assessment. Extracted data included the primary data based on the following: first author, year of publication, participants, age, gender, body mass index, followup time, type of surgery, localization method, analgesia used in nerve block, analgesia used in PACU, and analgesia used in the ward. The included studies evaluated pain score with similar scores like VAS or NRS which is a line with anchor statements on the left (no pain) and on the right (extreme pain). Therefore, we equate NRS with VAS in statistical analysis. Because there were different kinds of opioid drugs in different studies and some are intravenous opioid drugs, some are oral opioid drugs. To reduce heterogeneity, we have converted various opioids drugs into the same morphine (oral). Conversions of amounts of different opioids used were performed using a web-based opioid conversion calculator (https://globalrph.com/medcalcs/opioid-conversions-calcoriginal-single-agent/).

\section{Assessment of studies}

The studies' methodological quality was assessed following the instructions in the Cochrane Handbook for Systematic Reviews of Interventions.

\section{Statistical analysis}

RevMan software (version 5.3; The Cochrane Collaboration) was used for the analysis. We used a random-effects model for all analyses, as clinical heterogeneity was assumed to exist because of differences in standardization in anesthetic, nerve block techniques, diversity of shoulder surgeries performed, and the timing of assessment across studies. Data were summarized as the ratio of relative risk (rate of patient satisfaction, complications including the rate of subjective dyspnea, hoarseness, vomiting, local tenderness, Horner syndrome, and numb) or the difference between means (VAS at rest, VAS with movement, oral morphine equivalents use at $24 \mathrm{~h}$ and duration of PACU stay). Studies that did not report standard deviations (SDs) were calculated from $p$ values, confidence intervals, or standard errors. The results were considered as a statistically significant difference when $P$ values were less than 0.05 .

\section{Results}

The literature search identified 389 citations. Of these, 290 duplicates were removed. After reviewing the 99 remaining articles' titles and abstracts, we excluded 74 papers according to the inclusion and exclusion criteria; 25 full texts were retrieved. Because some articles did not compare the suprascapular nerve block with interscalene nerve block, five studies were excluded. Finally, we identified 1255 patients assessed in 17 randomized controlled trials $[1,3,7,11,20,21,25,28-31,34,35$, 40, 42-44] (Fig. 1). Study baseline characteristics and

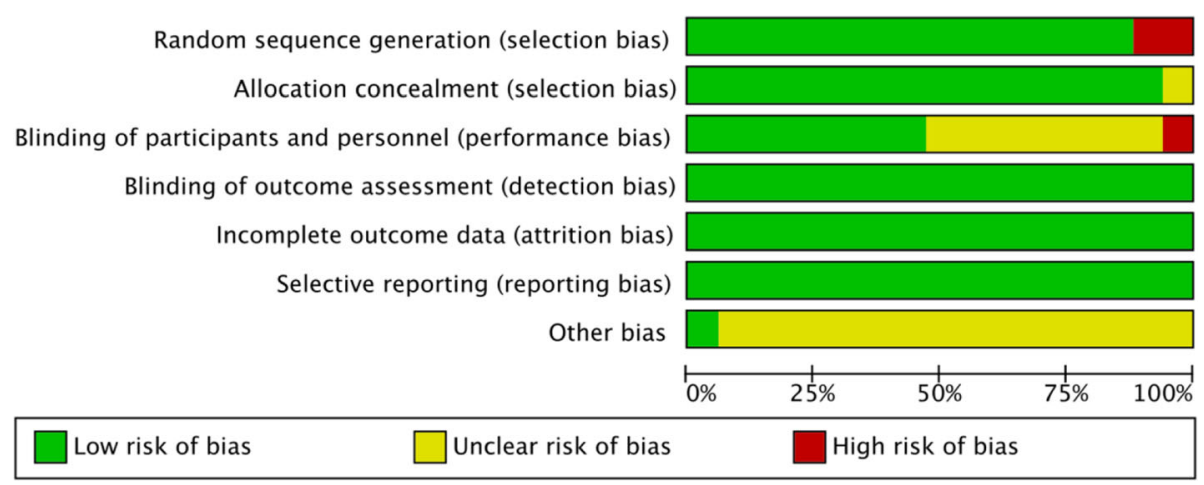

Fig. 3 The risk of bias graph. The overall quality of the included studies was considered adequate 


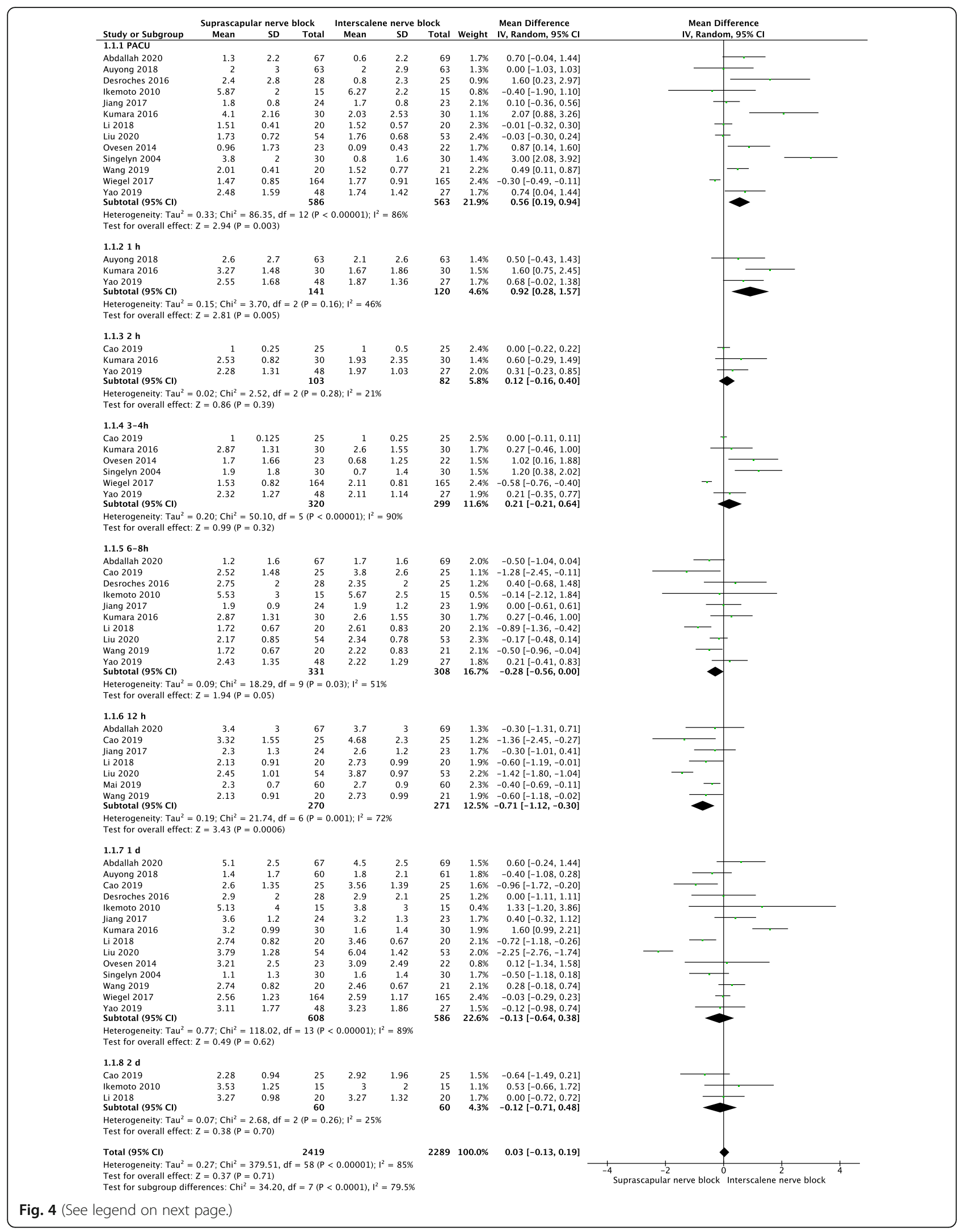


(See figure on previous page.)

Fig. 4 A forest plot diagram showing VAS at rest. The pooled results showed that SSNB group had higher VAS at rest in PACU (MD $=0.56,95 \%$ $\mathrm{Cl}[0.19,0.94], P=0.003)$ and $1 \mathrm{~h}$ after operation $(\mathrm{MD}=0.92,95 \% \mathrm{Cl}[0.28,1.57], P=0.005)$, however, lower VAS at $12 \mathrm{~h}$ after operation (MD $=$ $-0.71,95 \% \mathrm{Cl}[-1.12,-0.3], P=0.0006)$. No significant difference was found for $\mathrm{VAS}$ at rest $2 \mathrm{~h}$ after operation $(\mathrm{MD}=0.12,95 \% \mathrm{Cl}[-0.16,0.4], P=$ $0.39), 3-4 \mathrm{~h}(\mathrm{MD}=0.21,95 \% \mathrm{Cl}[-0.21,0.64], P=0.32), 6-8 \mathrm{~h}(\mathrm{MD}=-0.28,95 \% \mathrm{Cl}[-0.56,0.00], P=0.05), 1$ day $(\mathrm{MD}=-0.13,95 \% \mathrm{Cl}[-0.64,0.38]$, $P=0.62)$, and 2 days after operation (MD $=-0.12,95 \% \mathrm{Cl}[-0.71,0.48], P=0.7)$

general intervention information are summarized in Tables 1 and 2 .

The risk of bias summary and bias graph for RCTs is shown in Figs. 2 and 3. Fifteen studies adequately described the correct randomization. Sixteen studies demonstrated sufficient allocation concealment. Eight studies described the blinding of participants and personnel. All seventeen articles described the blinding of outcome assessment, retained complete outcome data, and avoided selective reporting. We rated as unclear risk of other bias because we cannot ignore other potential dangers of biases. As a result, there is a low or moderate risk of bias in most of the articles reviewed.

\section{Outcome \\ VAS at rest}

The pooled results showed that SSNB group had higher VAS at rest in PACU (MD $=0.56,95 \%$ CI $[0.19,0.94], P=$ 0.003 ) and $1 \mathrm{~h}$ after operation (MD $=0.92,95 \% \mathrm{CI}[0.28$, 1.57 ], $P=0.005)$, however, lower VAS at $12 \mathrm{~h}$ after operation (MD $=-0.71,95 \% \mathrm{CI}[-1.12,-0.3], P=0.0006)$. No significant difference was found for VAS at rest $2 \mathrm{~h}$ after operation (MD $=0.12,95 \% \mathrm{CI}[-0.16,0.4], P=0.39), 3-4 \mathrm{~h}$ $(\mathrm{MD}=0.21,95 \% \mathrm{CI}[-0.21,0.64], P=0.32), 6-8 \mathrm{~h}(\mathrm{MD}=$ $-0.28,95 \%$ CI $[-0.56,0.00], P=0.05), 1$ day $(\mathrm{MD}=-0.13$, 95\% CI $[-0.64,0.38], P=0.62)$, and 2 days after operation $(\mathrm{MD}=-0.12,95 \% \mathrm{CI}[-0.71,0.48], P=0.7)$ (Fig. 4).

\section{VAS with movement}

The pooled results showed that SSNB group had higher VAS with movement in PACU (MD $=1.05,95 \%$ CI [0.1, 2], $P=0.03$ ), however, lower VAS 8-12 h after operation $(\mathrm{MD}=-0.63,95 \% \mathrm{CI}[-1.11,-0.15], P=0.01)$. No significant difference was found for VAS with movement 4-6 h (MD $=0.4,95 \% \mathrm{CI}[-0.28,1.08], P=0.25)$, and 1 day after operation (MD $-0.47,95 \%$ CI $[-1.36,0.43]$, $P=0.3$ ) (Fig. 5).

\section{Opioid drugs consumption}

No significant difference was found for oral morphine equivalents use at $24 \mathrm{~h}(\mathrm{mg})(\mathrm{MD}=1.4,95 \% \mathrm{CI}[-1.53$, 4.33], $P=0.35$ ) (Fig. 6).

\section{Nerve block-related complications}

The pooled data showed that SSNB group had lower incidence of Horner syndrome $(\mathrm{MD}=0.06,95 \%$ CI $[0.02$, $0.22], P<0.0001)$, numb (MD $=0.05,95 \%$ CI $[0.01,0.33]$,
$P=0.002)$, subjective dyspnea $(\mathrm{MD}=0.4,95 \% \mathrm{CI}[0.17$, $0.95])$, hoarseness, $(\mathrm{MD}=0.31,95 \% \mathrm{CI}[0.1,0.97], P=$ 0.04). No significant difference was found for vomiting $(\mathrm{MD}=0.8,95 \% \mathrm{CI}[0.38,1.68], P=0.56)$, local tenderness $(\mathrm{MD}=0.9,95 \% \mathrm{CI}[0.27,3.02], P=0.87)$ (Fig. 7).

\section{Duration of PACU stay}

No significant difference was found for the duration of PACU stay $(\mathrm{MD}=-1.3,95 \% \mathrm{CI}[-6.83,4.23], P=0.65)$ (Fig. 8).

\section{Patient satisfaction}

The pooled data showed that no significant difference was found for the rate of patient satisfaction ( $\mathrm{MD}=3.45,95 \%$ CI $[0.67,17.68], P=0.14$ ) (Fig. 9).

\section{Discussion}

We only found two meta-analyses comparing SSNB with ISB. However, there is some difference between our study and the previous two meta-analyses. First, the inclusion standard is different. One meta-analysis by Kay [22] compared SSNB with ISB as well as anesthesia without a nerve block. Another meta-analysis by Hussain [19] included comparison of SSNB plus AXB and ISB. Second, the restriction of the previous meta-analysis to English language publications potentially limits the power obtained with the inclusion of non-English language studies. Third, the previous two studies did not separately evaluate the pain at rest and pain with movement. Under the current background of rapid recovery, patients need to move as soon as possible to achieve quick recovery, so it is essential to evaluate the pain with movement. Fourth, they did not analyze the duration of PACU stay and patient satisfaction. Thus, based on the current studies comparing SSNB with ISB during arthroscopic shoulder surgery, we only compare SSNB with ISB and include English language studies and Chinese RCTs. Moreover, our study added the analysis of pain at rest, pain with movement, duration of PACU stay, and patient satisfaction, which may provide a more exact conclusion and could be a supplement for the previous meta-analysis.

Our data of meta-analysis challenged the purported superiority of ISB over SSNB for shoulder surgery [12, $34,39,40]$. Interestingly, the rebound phenomenon of increased pain in ISB group in our meta-analysis was not found in the previous two meta-analyses. The postoperative 


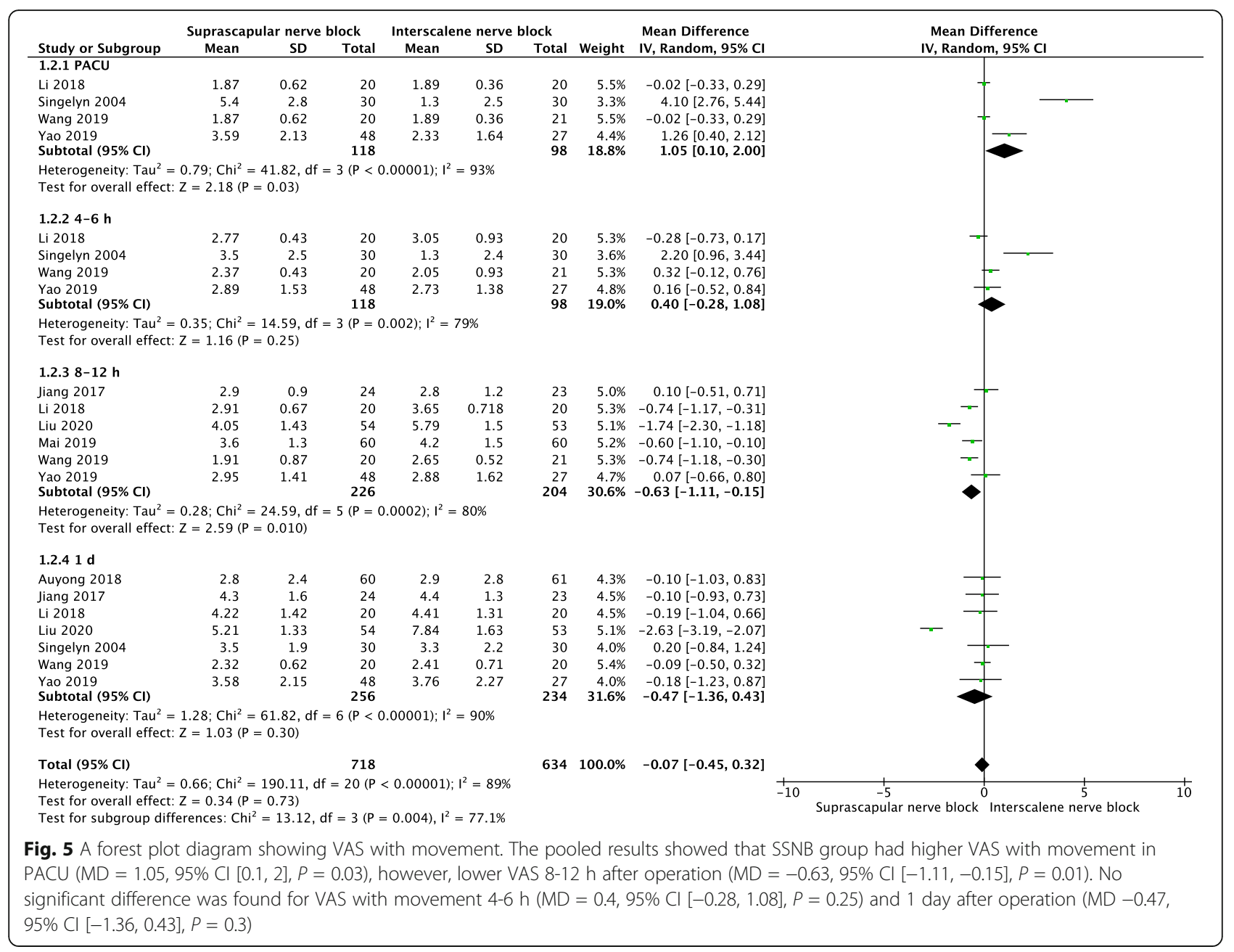

pain at rest and pain with movement at the individual time points suggested that ISB can provide better pain control that is limited to the PACU stay; however, there is a rebound phenomenon of increased pain in ISB group in the latter time. Compared with the ISB group, the SSNB group provides less pain control in the PACU stay, however, similar or superior pain control in the later time. There may be two reasons for the imperfect early pain control in the SSNB groups. First, the suprascapular nerve rarely has cutaneous innervation, and therefore the SSNB does not provide analgesia for the pain from skin incisions. Second, the suprascapular nerve supplies only $70 \%$ of the sensory fibers to the joint and capsule.

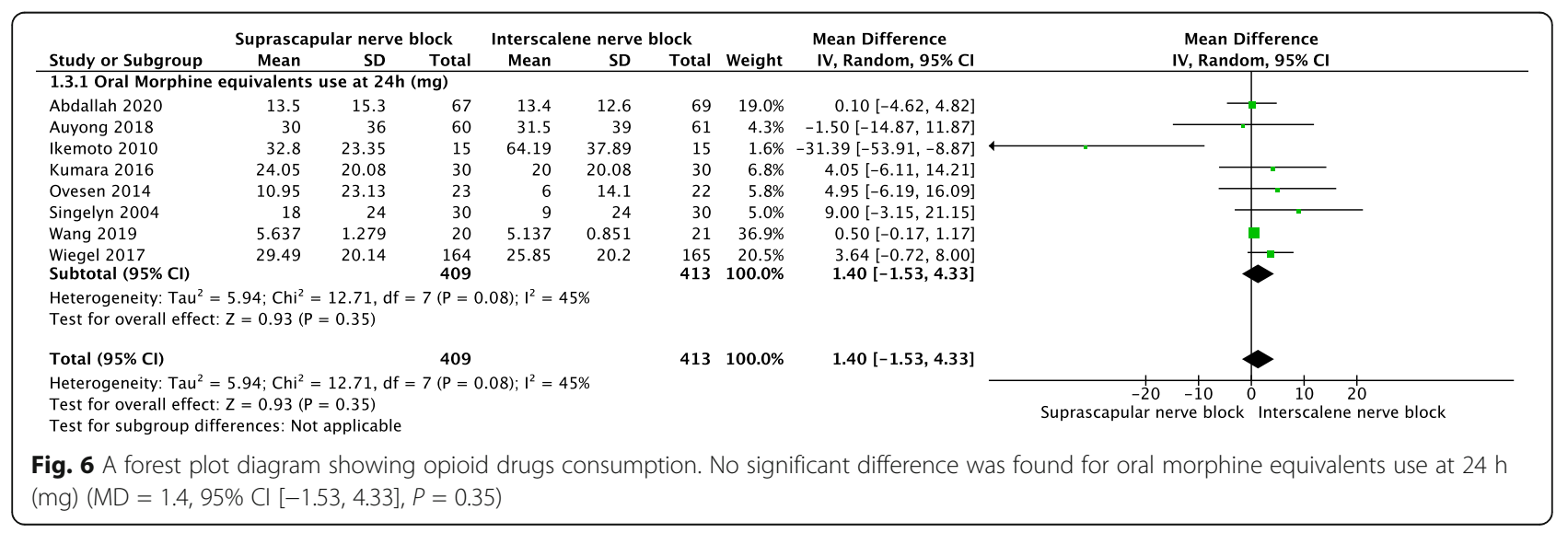




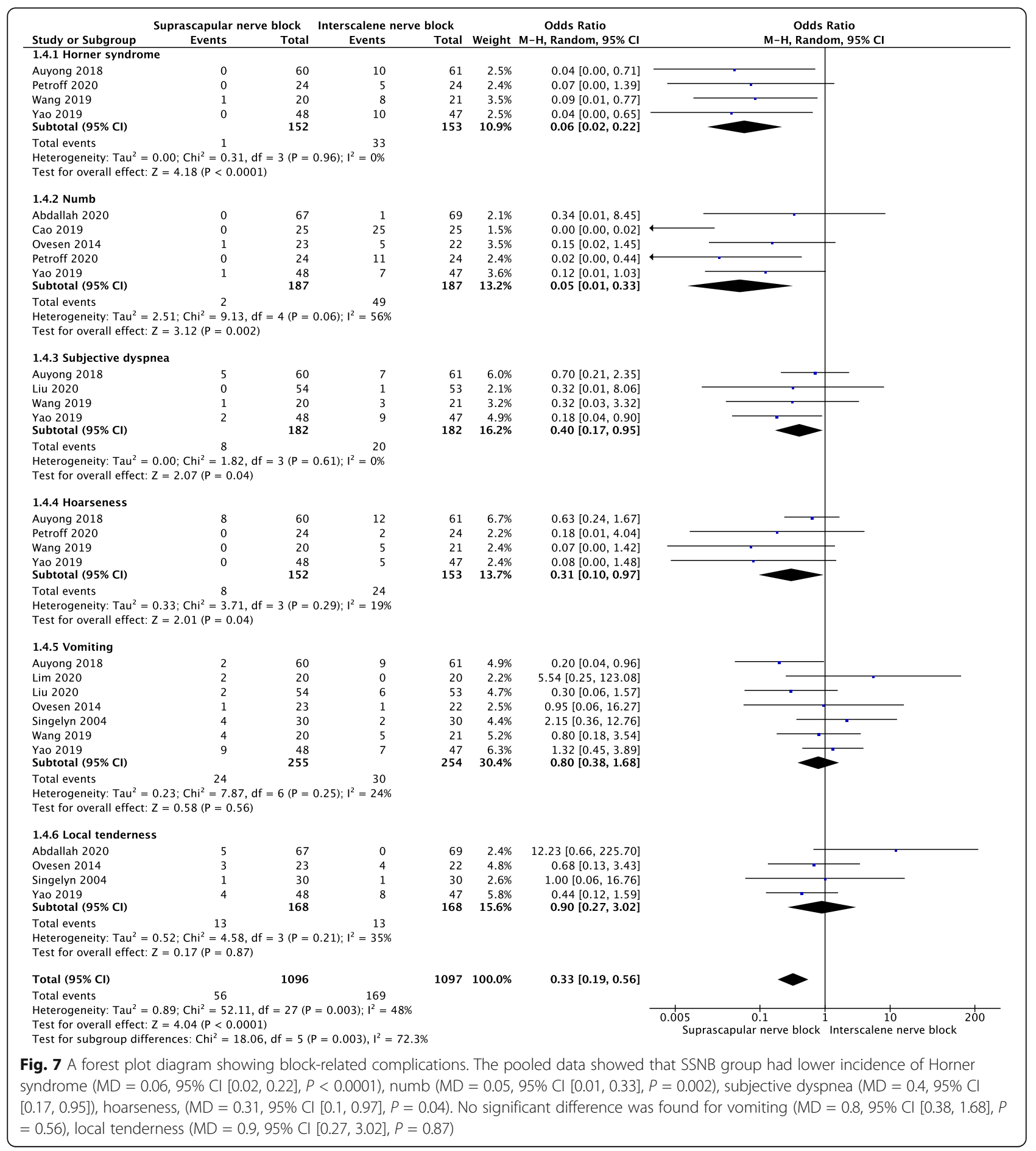

The remaining $30 \%$ of the joint and capsule is innervated by the axillary, supraclavicular, subscapular, and pectoral nerves $[8,13]$ rather than the suprascapular nerve.

Management of shoulder surgery pain is often accomplished by using opioids; however, their use is often associated with side effects such as vomiting, nausea dysphoria, respiratory depression, and hormonal effects
$[32,37]$. The present high-level evidence suggested that the blocks are not different for the critical analgesic measures, namely, the difference between SSNB and ISB in the postoperative oral morphine consumption at $24 \mathrm{~h}$. Likewise, the remaining analgesic outcome results, such as duration of PACU stay, patient satisfaction, and nerve block complications, including vomiting and local tenderness, were consistently not different between the two 


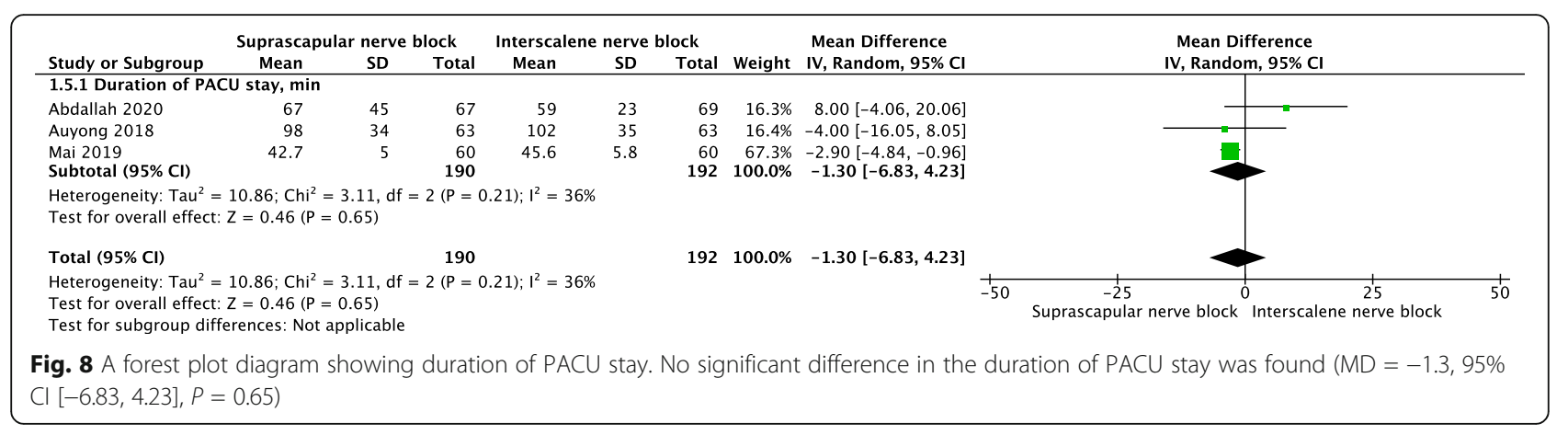

groups. In contrast, ISB was associated with a higher incidence of Horner syndrome, numb, subjective dyspnea, and hoarseness. From an anatomical perspective, the SSNB technique needs to perform blocks more distally along the brachial plexus, increasing the distance between block location and the phrenic nerve to decrease the phrenic nerve complications. Many studies also have shown that SSNB is a safe technique [19]. For example, the rate of minor complications was reported by only $0.6 \%(6 / 1005)$ [38]. Moreover, SSNB is an easy technique that can be performed using specific anatomic landmarks alone [33].

Though ISB provides superior pain control during the PACU stay, we did not find any significant difference between SNNB and ISB in terms of duration of PACU stay. Furthermore, no significant difference was found for patient satisfaction in SSNB and ISB, which may be explained by similar pain control in both nerve block techniques.

Our findings may have an impact on clinical practice. The minor analgesic advantages of ISB compared with the SSNB seem to be transient and limited to the immediate postoperative period (PACU stay). In contrast, the risk of block-related complications associated with ISB may outweigh its benefits in certain settings or patient populations, especially when SSNB can offer a safe and effective alternative in patients with severe chronic obstructive pulmonary disease [41], obstructive sleep apnea [10], and morbid obesity [16]. Our findings established the suprascapular block's clinical benefits as an attractive, effective treatment for postoperative pain in patients undergoing shoulder surgery.

\section{Limitations}

Our meta-analysis has limitations that should be acknowledged. First, heterogeneity was found across the included studies in terms of standardization in anesthetic, nerve block techniques, diversity of shoulder surgeries performed, and the timing of assessment, which precluded the pooling of many of outcomes. Second, some studies included in this review had smaller sample sizes, which may decrease the strength of their effect and limit external validity. Third, the number of the studies comparing the duration of PACU stay (three studies) and patient satisfaction (two studies) is too small. More adequately powered and better-designed RCT studies with these outcomes are needed to reach a firmer conclusion. Fourth, another bias inherent to the present study relates to the inability to blind the operator to the block technique being performed because of the interventions' nature.

\section{Conclusion}

ISB seems to offer minor analgesic advantages that are transient and limited to the immediate postoperative period. SSNB is equal or even better than ISB concerning postoperative pain control in the later time after operation. Furthermore, SSNB does appear to reduce the

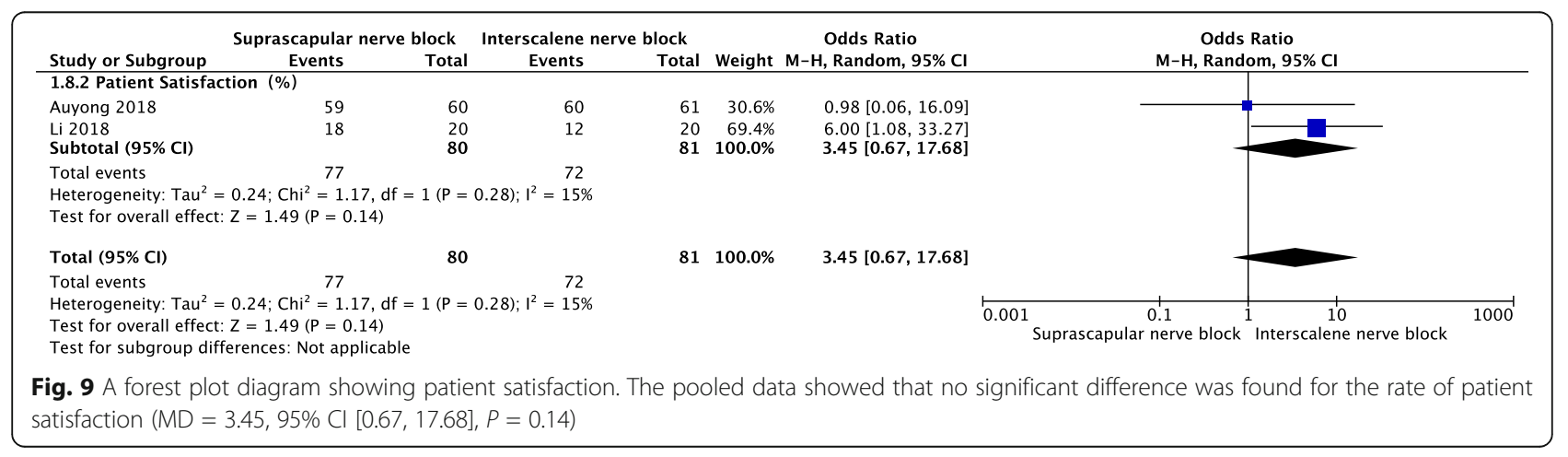


risk of Horner syndrome, numb, subjective dyspnea, and hoarseness. Our high-level evidence has established SSNB as an effective, safe, and clinically attractive alternative to ISB during arthroscopic shoulder surgery, especially for patients of severe chronic obstructive pulmonary disease, obstructive sleep apnea, and morbid obesity. Given our meta-analysis's relevant possible biases, we required more adequately powered and better-designed RCT studies with long-term follow-up to reach a firmer conclusion.

\section{Abbreviations}

Cis: Confidence intervals; RCTs: Randomized controlled trials; RR: Risk ratio; OR: Odds ratio; VMD: Weighted mean difference; BMI: Body mass index; VAS: Visual analog scale; NRS: Numerical rating scale; SSNB: Suprascapular nerve block; ISB: Interscalene block

\section{Acknowledgements}

Not applicable.

\section{Authors' contributions}

Changjiao Sun and Xu Cai: Conceptualization, Data curation; Formal analysis, Roles/Writing - original draft; Writing - review and editing. Qi Ma and Xiaolin Ji: Data collection; Investigation; Methodology. Xiaofei Zhang and Peng Yu: Resources; Software. Xu Cai and Huadong Yang (co-corresponding authors) Supervised the whole study. The authors read and approved the final manuscript.

\section{Funding}

None.

\section{Availability of data and materials}

The datasets generated and analyzed during the current study are available from the corresponding author on reasonable request.

\section{Declarations}

Ethics approval and consent to participate

Not applicable.

\section{Consent for publication}

Not applicable.

\section{Competing interests}

The authors declare that they have no competing interests.

\section{Author details}

'Department of Orthopedic, Beijing Tsinghua Changgung Hospital, School of Clinical Medicine, Tsinghua University, No. 168 Litang Road, Dongxiaokou Town, Changping District, Beijing 102218, China. ${ }^{2}$ Department of Anesthesia, Beijing Tsinghua Changgung Hospital, School of Clinical Medicine, Tsinghua University, No. 168 Litang Road, Dongxiaokou Town, Changping District, Beijing 102218, China. ${ }^{3}$ Department of Clinical Epidemiology and Biostatistics, Beijing Tsinghua Changgung Hospital, School of Clinical Medicine, Tsinghua University, No. 168 Litang Road, Dongxiaokou Town, Changping District, Beijing 102218, China. ${ }^{4}$ Department of Orthopedic, Wuhan University of Science and Technology Hospital, Qingling Street, Hongshan District, Wuhan 102218, China.

Received: 2 April 2021 Accepted: 2 June 2021

Published online: 11 June 2021

\section{References}

1. Abdallah FW, Wijeysundera DN, Laupacis A, Brull R, Mocon A, Hussain N, et al. Subomohyoid anterior suprascapular block versus interscalene block for arthroscopic shoulder surgery: a multicenter randomized trial. Anesthesiology. 2020;132(4):839-53. https://doi.org/10.1097/aln. 0000000000003132.
2. Al-Kaisy A, McGuire G, Chan WW, Bruin G, Peng P, Miniaci A, et al. Analgesic effect of interscalene block using low-dose bupivacaine for outpatient arthroscopic shoulder surgery. Reg Anesth Pain Med. 1998;23(5):469-73. https://doi.org/10.1097/00115550-199823050-00007.

3. Auyong DB, Hanson NA, Joseph RS, Schmidt BE, Slee AE, Yuan SC. Comparison of anterior suprascapular, supraclavicular, and interscalene nerve block approaches for major outpatient arthroscopic shoulder surgery: a randomized, double-blind, noninferiority trial. Anesthesiology. 2018;129(1): 47-57. https://doi.org/10.1097/aln.0000000000002208.

4. Bishop JY, Sprague M, Gelber J, Krol M, Rosenblatt MA, Gladstone JN, et al. Interscalene regional anesthesia for arthroscopic shoulder surgery: a safe and effective technique. J Shoulder Elbow Surg. 2006;15(5):567-70. https:// doi.org/10.1016/j.jse.2006.01.009.

5. Bogdanov A, Loveland R. Is there a place for interscalene block performed after induction of general anaesthesia? Eur J Anaesthesiol. 2005;22(2):10710. https://doi.org/10.1017/s0265021505000207.

6. Breu A, Eckl S, Zink W, Kujat R, Angele P. Cytotoxicity of local anesthetics on human mesenchymal stem cells in vitro. Arthroscopy. 2013;29(10):1676-84. https://doi.org/10.1016/j.arthro.2013.06.018.

7. Cao S, Wang J, Yan L, Gong W, Zhang Y, Fei W. Analysis of the effect of suprascapular nerve block guided by shoulder arthroscopy in postoperative analgesia of rotator cuff injury. Chin J Endoscopy. 2019;11:55-60.

8. Chan CW, Peng PW. Suprascapular nerve block: a narrative review. Reg Anesth Pain Med. 2011;36(4):358-73. https://doi.org/10.1097/AAP.0b013e31 82204 ec0.

9. Conn RA, Cofield RH, Byer DE, Linstromberg JW. Interscalene block anesthesia for shoulder surgery. Clin Orthop Relat Res. 1987;216:94-8.

10. D’Apuzzo MR, Browne JA. Obstructive sleep apnea as a risk factor for postoperative complications after revision joint arthroplasty. J Arthroplasty. 2012;27(8):95-8. https://doi.org/10.1016/j.arth.2012.03.025.

11. Desroches A, Klouche S, Schlur C, Bauer T, Waitzenegger T, Hardy P. Suprascapular nerve block versus interscalene block as analgesia after arthroscopic rotator cuff repair: a randomized controlled noninferiority trial. Arthroscopy. 2016;32(11):2203-9. https://doi.org/10.1016/j.arthro.2016.03.013.

12. Dhir S, Sondekoppam RV, Sharma R, Ganapathy S, Athwal GS. A comparison of combined suprascapular and axillary nerve blocks to interscalene nerve block for analgesia in arthroscopic shoulder surgery: an equivalence study. Reg Anesth Pain Med. 2016;41(5):564-71. https://doi.org/10.1097/aap. 0000000000000436

13. Fernandes MR, Barbosa MA, Sousa AL, Ramos GC. Suprascapular nerve block: important procedure in clinical practice. Rev Bras Anestesiol. 2012; 62(1):96-104. https://doi.org/10.1016/s0034-7094(12)70108-3.

14. Flohr-Madsen S, Ytrebø LM, Valen K, Wilsgaard T, Klaastad $\varnothing$. A randomised placebo-controlled trial examining the effect on hand supination after the addition of a suprascapular nerve block to infraclavicular brachial plexus blockade. Anaesthesia. 2016;71(8):938-47. https://doi.org/10.1111/anae.13504.

15. Fujimura N, Namba H, Tsunoda K, Kawamata T, Taki K, Igarasi M, et al. Effect of hemidiaphragmatic paresis caused by interscalene brachial plexus block on breathing pattern, chest wall mechanics, and arterial blood gases. Anesth Analg. 1995;81(5):962-6. https://doi.org/10.1097/00000539-199511000-00012.

16. Griffin JW, Novicoff WM, Browne JA, Brockmeier SF. Morbid obesity in total shoulder arthroplasty: risk, outcomes, and cost analysis. J Shoulder Elbow Surg. 2014;23(10):1444-8. https://doi.org/10.1016/j.jse.2013.12.027.

17. Hadzic A, Williams BA, Karaca PE, Hobeika P, Unis G, Dermksian J, et al. For outpatient rotator cuff surgery, nerve block anesthesia provides superior same-day recovery over general anesthesia. Anesthesiology. 2005;102(5): 1001-7. https://doi.org/10.1097/00000542-200505000-00020.

18. Harmon D, Hearty C. Ultrasound-guided suprascapular nerve block technique. Pain Physician. 2007;10(6):743-6.

19. Hussain N, Goldar G, Ragina N, Banfield L, Laffey JG, Abdallah FW. Suprascapular and interscalene nerve block for shoulder surgery: a systematic review and meta-analysis. Anesthesiology. 2017;127(6):998-1013. https://doi.org/10.1097/aln.0000000000001894.

20. Ikemoto RY, Murachovsky J, Prata Nascimento LG, Bueno RS, Oliveira Almeida LH, Strose E, et al. Prospective randomized study comparing two anesthetic methods for shoulder surgery. Rev Bras Ortop. 2010;45(4):395-9. https://doi.org/10.1016/s2255-4971(15)30386-4.

21. Jiang H, Wu Q, Tang Y, Zheng M, Chen L. Application of ultrasound-guided anterior suprascapular nerve block in the analgesia of shoulder arthroscopic surgery. J Clin Anesthesiol. 2017;12:1192-5. 
22. Kay J, Memon M, Hu T, Simunovic N, Duong A, Paul J, et al. Suprascapular nerve blockade for postoperative pain control after arthroscopic shoulder surgery: a systematic review and meta-analysis. Orthop J Sports Med. 2018; 6(12):2325967118815859. https://doi.org/10.1177/2325967118815859.

23. Konradsen LKP, Larsen VHBH. Suprascapular nerve block or interscalene brachial plexus block for pain relief after arthroscopic acromioplasty. Ambul Surg. 2009;15:16-9.

24. Krone SC, Chan WW, Regan J, Peng P, Poate EM, McCartney C, et al. Analgesic effects of low-dose ropivacaine for interscalene brachial plexus block for outpatient shoulder surgery-a dose-finding study. Reg Anesth Pain Med. 2001;26(5):439-43. https://doi.org/10.1053/rapm.2001.25914.

25. Kumara AB, Gogia AR, Bajaj JK, Agarwal N. Clinical evaluation of post-operative analgesia comparing suprascapular nerve block and interscalene brachial plexus block in patients undergoing shoulder arthroscopic surgery. J Clin Orthop Trauma. 2016;7(1):34-9. https://doi.org/10.1016/j.jcot.2015.09.003.

26. Laurila PA, Löppönen A, Kanga-Saarela T, Flinkkilä T, Salomäki TE. Interscalene brachial plexus block is superior to subacromial bursa block after arthroscopic shoulder surgery. Acta Anaesthesiol Scand. 2002;46(8): 1031-6. https://doi.org/10.1034/j.1399-6576.2002.460818.x

27. Lenters TR, Davies J, Matsen FA 3rd. The types and severity of complications associated with interscalene brachial plexus block anesthesia: local and national evidence. J Shoulder Elbow Surg. 2007;16(4):379-87. https://doi. org/10.1016/j.jse.2006.10.007.

28. Li T. Comparison of two ultrasound-guided nerve block techniques in shoulder arthroscopic surgery [Master]. Kunming: Kunming Medical University; 2018.

29. Lim YC, Koo ZK, Ho W, Chang SS, Manohara S, Tong QJ. Randomized, controlled trial comparing respiratory and analgesic effects of interscalene, anterior suprascapular, and posterior suprascapular nerve blocks for arthroscopic shoulder surgery. Korean J Anesthesiol. 2020;73(5):408-16. https://doi.org/10.4097/kja.20141

30. Liu P. The effect of suprascapular nerve block on patients undergoing arthroscopic shoulder surgery. Zhejiang J Traumat Surg. 2020;25:589-90.

31. Mai Z. Application of ultrasound-guided anterior suprascapular nerve block in the analgesia of shoulder arthroscopic surgery. J Minimal Invasive Med. 2019;14:803-804+820

32. Manchikanti L, Fellows B, Ailinani H, Pampati V. Therapeutic use, abuse, and nonmedical use of opioids: a ten-year perspective. Pain Physician. 2010; 13(5):401-35.

33. Matsumoto D, Suenaga N, Oizumi N, Hisada Y, Minami A. A new nerve block procedure for the suprascapular nerve based on a cadaveric study. J Shoulder Elbow Surg. 2009;18(4):607-11. https://doi.org/10.1016/j.jse.2009.01.005.

34. Ovesen JF-JTC. A comparison of subacromial bursae block, suprascapular nerve block and interscalene brachial plexus block after arthroscopic shoulder surgery. Pain Stud Treat. 2014;2(03):107-12. https://doi.org/10.4236/ pst.2014.23017.

35. Petroff D, Wiegel M, Pech V, Salz P, Mrongowius J, Reske AW. Differential lung ventilation assessed by electrical impedance tomography in ultrasound-guided anterior suprascapular nerve block vs. interscalene brachial plexus block: a patient and assessor-blind, randomised controlled trial. Eur J Anaesthesiol. 2020;37(12):1105-14. https://doi.org/10.1097/eja. 0000000000001367.

36. Ritchie ED, Tong D, Chung F, Norris AM, Miniaci A, Vairavanathan SD. Suprascapular nerve block for postoperative pain relief in arthroscopic shoulder surgery: a new modality? Anesth Analg. 1997;84(6):1306-12. https://doi.org/10.1097/00000539-199706000-00024.

37. Seyfried O, Hester J. Opioids and endocrine dysfunction. Br J Pain. 2012;6(1): 17-24. https://doi.org/10.1177/2049463712438299.

38. Shanahan EM, Shanahan KR, Hill CL, Ahern MJ, Smith MD. Safety and acceptability of suprascapular nerve block in rheumatology patients. Clin Rheumatol. 2012;31(1):145-9. https://doi.org/10.1007/s10067-011-1813-3.

39. Shin YDHJ. The effect of sono-guided brachial plexus block on postoperative pain control for arthroscopic shoulder surgery: comparison with general anesthesia. Anesth Pain Med. 2010;5:183-6.

40. Singelyn FJ, Lhotel L, Fabre B. Pain relief after arthroscopic shoulder surgery: a comparison of intraarticular analgesia, suprascapular nerve block, and interscalene brachial plexus block. Anesth Analg. 2004;99:589-92. https://doi. org/10.1213/01.Ane.0000125112.83117.49.

41. Urmey WF, Talts KH, Sharrock NE. One hundred percent incidence of hemidiaphragmatic paresis associated with interscalene brachial plexus anesthesia as diagnosed by ultrasonography. Anesth Analg. 1991;72(4):498503. https://doi.org/10.1213/00000539-199104000-00014.

42. Wang Y. Study on the effect of two continuous nerve blocks on the respiratory function of patients after shoulder arthroscopy [Master]. Kunming: Kunming Medical University; 2019.

43. Wiegel M, Moriggl B, Schwarzkopf P, Petroff D, Reske AW. Anterior suprascapular nerve block versus interscalene brachial plexus block for shoulder surgery in the outpatient setting: a randomized controlled patientand assessor-blinded trial. Reg Anesth Pain Med. 2017;42(3):310-8. https:// doi.org/10.1097/aap.0000000000000573.

44. Yao J, Huang $\mathrm{H}$, Huang S, Zhang Z. Application effect of suprascapular nerve block in patients undergoing arthroscopic rotator cuff repair surgery. Tianjin Med J. 2019:47:851-4.

\section{Publisher's Note}

Springer Nature remains neutral with regard to jurisdictional claims in published maps and institutional affiliations.
Ready to submit your research? Choose BMC and benefit from:

- fast, convenient online submission

- thorough peer review by experienced researchers in your field

- rapid publication on acceptance

- support for research data, including large and complex data types

- gold Open Access which fosters wider collaboration and increased citations

- maximum visibility for your research: over $100 \mathrm{M}$ website views per year

At $\mathrm{BMC}$, research is always in progress.

Learn more biomedcentral.com/submissions 